\title{
Choque de paradigmas: análisis a las prohibiciones de Tamburini y Retz a diversas tesis modernas
}

\author{
Juan Camilo Hernández Rodríguez,*** \\ Jhonatan Pérez Bedoya ${ }^{* * *}$
}

\section{Resumen}

Este trabajo tiene como objetivo comentar algunas prohibiciones del padre Miguel Ángel de Tamburini y del padre Francisco Retz (dos filósofos escolásticos modernos) explicando los conceptos fundamentales de dichas prohibiciones a través de un método analítico y relacionándolos posteriormente bajo un método sintético con los argumentos presentados. Esto último permitirá realizar una reconstrucción de las prohibiciones cuyo ensamble se consolidará en argumentos breves. Asimismo, evaluar cuáles pueden ser las causas o los fundamentos que subyacen en las prohibiciones mismas, es decir, evaluar las causas de su veto. Finalmente, determinar las implicaciones filosóficas de las

* Citar como: Hernández Rodriguez, J. C. y Pérez Bedoya, J. (2018). Choque de paradigmas: análisis a las prohibiciones de Tamburini y Retz a diversas tesis modernas. Cuadernos de Filosofía Latinoamericana, 39(119), 47-76. DOI: http://www.doi.org/10.15332/25005375.5050

* Juan Camilo Hernández Rodríguez. Licenciado en Filosofía de la Universidad Pedagógica Nacional. Bogotá, Colombia. Orcid: http://orcid.org/0000-0001-6675-3636. Correo: Ifl_jchernandezr540@ pedagogica.edu.co

** Jhonatan Pérez Bedoya. Licenciado en Filosofía y licenciado en español e inglés de la Universidad Pedagógica Nacional. Bogotá, Colombia. Orcid: https://orcid.org/0000-0002-8705-6642. Correo: Ifl_jperezb988@ pedagogica.edu.co 
prohibiciones desde Descartes, Leibniz y Spinoza y sus correspondientes visiones de la Creación, la voluntad, el determinismo y el principio de individuación.

Palabras clave: filosofía moderna, filosofía escolástica, creación, libertad e individuación.

\section{Paradigm shock: analysis to the prohibitions of Tamburini and Retz to diverse modern thesis}

\section{Abstract}

This work aims to comment on some prohibitions of the father Miguel de Tamburini and Father Retz (two modern scholastic philosophers), explaining fundamental concepts of these prohibitions under an analytical method and relating them under a synthetic method through the theses exposed. The latter will allow making a reconstruction of prohibitions whose assembly will consolidate into brief arguments. Second, to assess what may be the underlying causes or fundamentals of the prohibitions themselves, that is, to assess why those theses were banned. Finally, to determine, from the positions of Descartes, Leibniz and Spinoza, the philosophical implications of their corresponding visions of creation, will, determinism, and the principle of individuation.

Keywords: modern philosophy, scholastic philosophy, creation, freedom and individuation.

\section{Introducción}

Con la llegada del Renacimiento a Europa con autores como Telesio, Bacon, Descartes, Spinoza y Leibniz, una revolución epistemológica y metafísica se estaba gestando; conceptos como la existencia, la libertad, la voluntad divina y la individuación, entre otros, estaban siendo explicados de una manera no trascendente (a partir de Dios), sino inmanente (a partir de la naturaleza misma). En la Colonia, como lo menciona Salazar Bondy (1968): 
[...] La filosofía oficialmente difundida y protegida fue la Escolástica, en su tardía versión española a la que, si bien no faltaron algunas cumbres, como Suárez, no se puede considerar una vía típica del pensamiento moderno. Además de oficial y de centrada en los intereses europeos y particularmente españoles, esta primera filosofía hispanoamericana es, pues, un pensamiento conservador, antimoderno. (Salazar Bondy, p. 12)

Según Salazar Bondy, este pensamiento antimoderno puede ser la causa de que en Hispanoamérica no se haya consolidado una filosofía original (p. 13). Por ello, es necesario revisar este conflicto entre la perspectiva escolástica y la moderna, no tanto para comprender dicha transformación en Europa, sino para comprender cómo este pensamiento conservador y antimoderno posiblemente forjó las bases de una "nueva" filosofía escolástica en Latinoamérica - específicamente, en Colombia- y un cierto ánimo de preservación de los ideales escolásticos ortodoxos (en especial, el tomista) en autores como Mateo Mimbela (2004), Francisco Javier Trías (2005) o Juan Martínez de Ripalda (2007). Así, este ejercicio nos permitirá comprender la historia de nuestro pensamiento filosófico.

Creemos que las prohibiciones a analizar son un claro ejemplo de este movimiento antimoderno, pues, si bien dentro de las prohibiciones mismas no se explicita en qué parte de la obra del autor se expresan tales citas contrarias a la filosofía escolástica ortodoxa, sí se puede evidenciar por el título de las prohibiciones y por el contenido que en ellas está implícito las tesis de Descartes, Spinoza y Leibniz. Así, esta hipótesis será la que regirá el siguiente estudio.

\section{Análisis lógico de las prohibiciones}

Como se mencionó anteriormente, el procedimiento a realizar en el análisis de las prohibiciones será por medio de tres momentos: primero, la selección de las prohibiciones; segundo, la extracción y definición de los conceptos claves a partir de las fuentes primarias; y tercero, una reconstrucción de los posibles argumentos que fueron prohibidos a partir de dichos conceptos y de las prohibiciones.

\section{Prohibiciones seleccionadas}

Estas son las tesis prohibidas que se escogieron del “Anexo 1", por Tamburini (2004, pp. 60-61): 
$\$ 6$. Los modos o accidentes en cualquier sujeto, una vez producidos, no necesitan más de la acción positiva por cuya causa ellos se conservan; sino que ellos deben permanecer hasta que sean destruidos por la acción positiva de una causa externa.

$\$$ 8. Ninguna sustancia (ni espiritual ni corporal) puede regresar a la nada, ni siquiera por obra de Dios.

$\$$ 9. La esencia de cualquier cosa depende de la libre voluntad de Dios; de tal manera que en cualquier otro orden que Él hubiera dado libremente a las cosas, la esencia y las propiedades de esta serían distintas de lo que son ahora, por ejemplo: las materias, los espíritus, los círculos, etc.

15. Solo puede existir un único mundo.

Estas son las prohibiciones de Tamburini del “Anexo 2" que se escogieron (2004, p. 64):

$\$ 1$. Que la voluntad de Dios, eficaz y absolutamente (o por decreto) predefine inmediatamente y de forma determinada una cosa, bien sea para todas y cada acto, o bien, a los efectos de las causas segundas.

$\$ 2$. Que esta predefinición sea absolutamente necesaria para que las causas segundas lleguen al acto.

Por último, estas son las dos tesis escogidas del “Anexo 3”, de Retz (2004, p. 68):

$\$$ 8. La materia y la forma en su composición natural no se unen físicamente de manera intrínseca, ni por sus entidades, ni por nexos distintos.

$\$ 10$. Lo que existe, y en un instante no está identificado estrictamente de manera física con otro, puede en otro instante existir sin que estricta y físicamente esté identificado con otro ${ }^{1}$.

1 Las citas de estos anexos se hacen desde el texto original. La traducción es propia y sigue a por Fajardo y Argote. 


\section{Definición de conceptos claves}

Expuestas las tesis a analizar, pasáremos a definir los conceptos claves - de manera similar a como lo hace Spinoza- que se consideran necesarios a analizar de manera filosófica. De esta manera, se evitará de antemano que se genere confusión cuando se realice la discusión entre los paradigmas medievales y modernos.

I. Creación (ברא/bârâ): acto divino ${ }^{2}$ que genera el ser de todas las cosas. Es un verbo solo predicable a Dios (BJ, Gén. 1:1, glosa; 1:27; 2:3; Deut., 4:32; Sal. 51:12; Is. 43:1; 43:15; De Aquino, I, q. 45, a. 1, ad. 1; a. 5, sol.).

II. Nada (ויאמ/nihil): antecedente de la creación (creatio ex nihilo en 2 Macab., 7:28), no material, sino de orden (De Aquino, q. 45, ad.3) $]^{3}$.

III. Existir ('ex-sistere" ): se refiere al ente que existe en virtud de su posicionamiento fuera de algo a partir de la creación, esto es, su raíz: Dios (san Agustín, 1958, t. 2, XIV, 13, \$2; De Saint-Victor, 1958, IV, c. 12/f. 160b9-160c20; De Aquino, 1951/2001a, I, q. 45, aa. 1-2).

2 Aclárese que este predicado (crear/ser creado) solo es posible en tanto que corresponda a Dios, pues crear es un acto necesariamente ex nihilo: "Te ruego, hijo, que mires al cielo y a la tierra y, al ver todo lo que hay en ellos, sepas que a partir de la nada lo hizo Dios* y que también el género humano ha llegado asi a la existencia" (BJ, II Macabeos, 7: 28), agregando esta glosa el traductor: "De la nada, literalmente no de cosas existentes" (p. 625). No debe confundirse con 'transformación', pues tan solo es el cambio de algo que ya estaba dado. La creación, por otra parte, no es antecedida por nada (cfr. De Aquino, 2001, q. 45, ad. 1).

3 No debe confundirse con 'no ser', pues "incluso de lo que no es digamos [del no ser] que es 'algo que

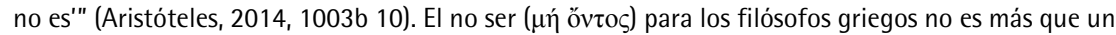
modo (Aristóteles) o región (Platón, 2013, 257b 4-5) del ser. "[']Nada['] suele venir contrapuesta a algo; pero [']algo['] es un ente determinado, que se diferencia de otro algo; es asi pues, igualmente, la nada contrapuesta a algo, la nada de cierto algo, una nada determinada. Aqui hay que tomar empero a la nada tiene dentro de su simplicidad indeterminada; la nada puramente en y para sí. -El no ser contiene referencia al ser; no es por lo tanto la pura nada, sino la nada tal como está ya en el devenir" (Hegel, 2011, WdL, I, 45). Aunque "[...] la nada es la negación a todo ser" (De Aquino, 2001, q. 45, sol.), no es igual a decir que es el 'no ser', sino que se refiere más bien a una relación de respectividad; es algo similar a decir "antes de esto no había nada". No es un estado distinto de la cosa (puesto que seria transformación), sino que es algo previo a la existencia misma del ente.

4 'Sistere' es el verbo en infinitivo de 'sisto', el equivalente a $\theta \dot{\varepsilon} \sigma ı \varsigma(\varepsilon ̌ \chi \omega)$ : "estar posicionado en" (Lewis, Short \&t Freund, 1956, voz 'sisto'; Lydell \& Scott, 1996, voz ě $\chi \omega)$. Caso igual pasa con el alemán, donde, de hecho, 'Dasein' ('existencia') es un verbo separable (sein [...] da) que indica "ser/estar ahi" (Fuentes, 2002, p. 802, voz 'da': sein). 
IV. Ente (ens): el todo o el compuesto. Un ente puede ser en modo primero (substancia primera), expresando una realidad concreta de un individuo o en modo segundo (substancia segunda), expresando un género (De Aquino, 1963, c. 1). Ente es aquello cuyo acto es existir (De Saint-Victor, 1958, IV, c. 12), puesto que al ser creado su ser es otorgado al momento de informar a la materia, generando la substancia material. Así, es un compuesto entre el ser (a través de la forma) y la quiddidad (a través de la materia), generando una relación hilemórfica: la substancia. No debe confundírsele con el tò őv (lo que es...) griego, pues este último tiene una doble connotación: predicativa ( $\tau \tilde{\omega} \nu \lambda \varepsilon \gamma o \mu \varepsilon \dot{v}$ ov ["lo que se dice

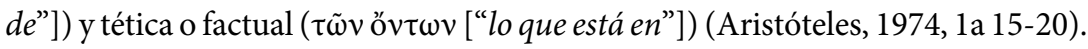
El ente atiende más a esta segunda acepción, más que a la primera ${ }^{5}$.

V. Ser (Esse): principio intrínseco del ente que es otorgado al momento de su creación. El ser es anterior al ente, puesto que es su causa, $y$, dado que su condición de causa es previa a la creación, no puede aprehendérsela por medio del intelecto, sino tan solo intuírsela (por cinco vías, según Tomás [De Aquino, 1951/2001a, I, qq. 44-45]).

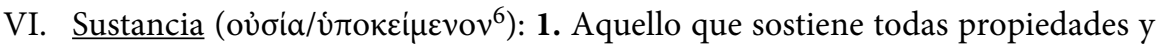
atributos de una cosa; “[...] yacer, estar debajo, servir de base” (Lydell \& Scott,

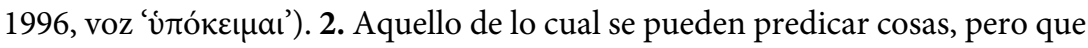
no es predicado de nada (Aristóteles, 2012, 2a 10/2014, 1017b 15). 3. Aquello que es en sí y se concibe por sí (Aristóteles, 2014, 1017a 20; Spinoza, 2000, def. 3/OP, 1). 4. Aquello cuya esencia implica existencia (Descartes, 1989, I, $\$ 51$; Aristóteles 2014, $\Delta$, 1017b 23-27). 5. Un ser capaz de acción (Leibniz, 1982e, §1/GP, VI, 598), es decir, que tiene/está en la potencia de actuar/llegar al acto (Aristóteles, 2014,

5 Esto puede explicar por qué surge el problema de los universales: si la verdad adquiere un carácter ontológico (está en Dios), aquellos juicios universales o abstractos deberian tener un ubi, deberian existir. Dado que el concepto de ser como $\tau \tilde{\omega} v$ öv $\tau \omega v$ es privilegiado por los medievales por encima

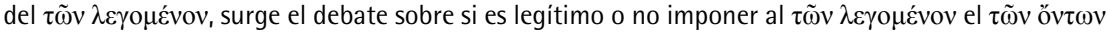
(véase: Beuchot, 1981 y De Aquino, 1975, q. 1).

6 Aunque en la teoría aristotélica la ov̉oía (lo propio/verdadero/permanente [Lydell \& Scott, 1996, voz

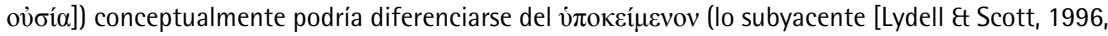

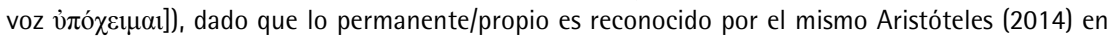
Met. Z, c. 1 como lo subyacente, se tomarán como lo mismo. Esto, en gran medida porque la tradición

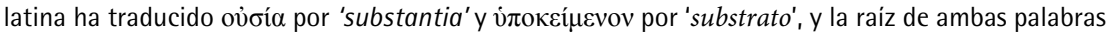
(sto y sterno) con el prefijo 'sub' terminan significando lo mismo: "lo que está debajo de" (Lewis, Short \& Freund, 1956, voces 'substo'y 'substerno'). 
1017a35-1017b8). 6. Estructura, compuesto o unión entre materia y forma (De Aquino, 1963, c. 2; 1951/2001a; I, q. 66).

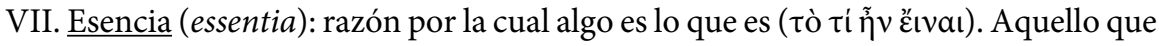
permanece en la substancia a pesar de los cambios. Autores, como Tomás, afirman que la substancia segunda no tiene esencia. Así, 'hombre' no tiene esencia; no obstante, el mismo Aristóteles afirma que sí es posible afirmar una esencia de un género; en este caso, la de 'ser racional'. Por esta razón, se entenderá esencia por el principio "identificatorio" de alguna cosa respecto a su género" ${ }^{7}$

VIII. Quiddidad: el principio según el cual esa cosa es esa y no otra ( $\tau$ ó $\delta \varepsilon \tau i)$. Se refiere

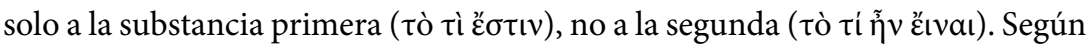
Tomás (1963, c. 2, $\$ \$ 4-5)$, la esencia solo es predicable del ente real, por ello quiddidad y esencia son sustituibles para él.

IX. Modo: accidente de una substancia. Aquella propiedad contingente de una cosa (Aristóteles, 2014, $\Delta$, 1017a 9-10; Spinoza, 2000, I, def. 5/OP, 1).

X. Necesario (ávaүкaĩov): aquello que por fuerza no puede ser de otra manera (Aristóteles, 2014, $\Delta, 1015 \mathrm{a} 33$ ), o bien, aquello que “[...] sería contradictorio suponer como no existente" (Avicena, 1950, c. 14, p. 114). Necesario se puede decir de dos maneras: por sí y por otro. El primero es esencial y el segundo, condicional (Avicena, 1950, c. 14, pp. 114-115; De Aquino, 1951/1951/2001a, I, q. 25, a. 3, sol.). Así, no es necesario a Dios crear el mundo (pues es posible pensárselo como no creador), pero si lo crea es necesario que sea el mejor de los mundos posibles (pues pensar lo contrario implicaría que el Ser perfecto ha creado algo imperfecto, lo cual es contradictorio).

\section{Reconstrucción de los posibles argumentos prohibidos}

Como se dijo anteriormente, tres temas son rescatados de estas prohibiciones de manera temática: la creación y la relación existencial que hay entre creador y criatura; la relación entre determinación y voluntad divina; y la discusión acerca

7 Un ejemplo que podria clarificar esta diferenciación sería la pregunta "¿qué hace al hombre ser hombre?", en contraste con "¿qué hace a Pedro ser Pedro, diferenciándolo de los demás hombres?". La primera sería la esencia; la segunda, la quiddidad. 
del principio de individuación. Así, se intentará mostrar cómo en cada anexo se ven respectivamente estos temas y cómo es posible hilarlos entre sí a partir de los siguientes argumentos:

Primero: si se establece una determinación a la voluntad divina, entonces Dios no es libre, lo que implica que no es omnipotente y, como diría Epicuro (citado por Hospers, 1990, p. 3), si no es omnipotente, ¿por qué llamarlo Dios? Así, si se le quita su omnipotencia dejaría de ser lo que es (el ser absolutamente perfecto), y, por lo tanto, se negaría su existencia.

Decir que, posterior a la creación, los entes ya no necesitan del Ser creador (Tamburini, 2004, anexo 1, \$6) implica negarle omnipotencia y, a su vez, negar su existencia. Además, afirmar que es imposible la destrucción absoluta del ser creado (es decir, el retorno a la nada [an. $1, \$ 8]$ ) implica negar la omnipotencia divina; por lo cual se puede deducir lo ya mencionado. También niega la omnipotencia de Dios - y a su vez, su existencia - al afirmar que el orden en que Dios crea las cosas determina la esencia de las cosas (an. $1, \S 9$ ), pues le está quitando a Dios la posibilidad de cambiar el orden conservando su esencia. También lo es afirmar que solo un mundo puede ser creado por Él (an. 1, $\$ 15$ ), pues le quita la posibilidad de crear otros. En otras palabras, dado que todas estas tesis niegan la omnipotencia y la existencia divina, deben ser prohibidas.

Segundo: además de recibir las mismas críticas alrededor del argumento anterior, afirmar que las cosas ya tienen predefinidos o determinados sus efectos o acciones (Tamburini, 2004, an. 2, \$1) y, que, además, esta es una condición necesaria para su acción (Tamburini, 2004, an. 2, \$2), implica negar el libre albedrío que ofrece Dios al momento de crear el mundo, y, a su vez, negaría la libertad del hombre; lo cual es indeseable. Esto último implica ir en contravía con san Agustín (1947a) o santo Tomás (1951/2001a, I, q. 83), generando una ruptura con unas de las principales autoridades de la Iglesia y, a su vez, se pierde la explicación de por qué el hombre, conociendo el mal, lo sobrecoge por encima del bien (san Agustín, 1947b).

Tercero: pensar a la materia de manera distinta a "la pura potencialidad que es informada ${ }^{8}$ por el Ser creador" (De Aquino, 2001b, III, q. 77) implica romper con

8 Entiéndase en adelante "informado/a" como: "que ha recibido su forma por...". 
el principio de individuación y, a su vez con la relación existencial misma que se genera entre el Ser creador y el ser creado. Así, teniendo en cuenta los anteriores argumentos, parece necesario darles mayor fuerza a las prohibiciones sustentándolas en explicaciones más amplias. Así, examinaremos qué conflicto antecede o subyace a estas tesis, esto es, contra quien están dirigidas. Por ello, se exige un análisis riguroso tanto de los antecedentes como de las tesis modernas para encontrar sus puntos de conflicto.

\section{Antecedentes a las prohibiciones}

De acuerdo con lo anterior, se presentarán las explicaciones de la doctrina oficial (tomista) alrededor de los temas centrales en las prohibiciones: la creación, la voluntad y la libertad, y el principio de individuación.

\section{El acto creador y conservador de Dios}

Según la teoría cristiana escolástica, la creación del mundo se establece como una

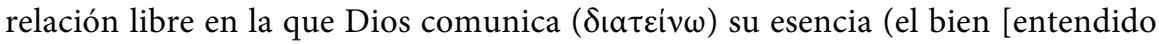
como “perfección”]) en la existencia (Pseudo-Dionisio, 1990, I, c. IV, $§ 1 /$ s. 145.6; De Aquino, 1951/2001a, I, q. 44, a. 4, sol.). Es decir, a Dios, “[...] no le corresponde actuar para adquirir algún fin, sino que tan sólo intenta comunicar su perfección, que es su bondad” (De Aquino, 1951/2001a,, I, q. 44, a. 4, sol). Así, a la voluntad de Dios solo le corresponde comunicar el bien que le es propio a su esencia.

\footnotetext{
Dios no sólo se quiere, sino que también quiere lo distinto a Él. Esto resulta claro por la comparación que antes se puso (a. 1). Pues una cosa natural no sólo tiene inclinación natural con respecto al propio bien, para conseguirlo si no lo tiene y para descansar en él si lo tiene; sino para difundir el propio bien en otros en la medida de lo posible. Por lo cual, vemos que todo agente, en cuanto está en acto y es perfecto, hace lo semejante a él. Por eso, en la razón de voluntad entra que el bien poseído se comunique a los demás en la medida de lo posible. (De Aquino, 1951/2001a, I, q. 19, a. 2, sol.)
}

Dado que su relación con la criatura es por comunicación, no es posible que la creación se dé por participación, ya que la participación es una relación del todo con las partes (interna), mientras que la comunicación es una relación virtual (externa). De esto se 
concluye que, la relación es unidireccional y que la existencia de los entes depende en sentido absoluto de Dios y no de ellas mismas, pues la razón de ser de su existencia es dicha comunicación divina. Si en algún momento Dios dejase de comunicar el bien las cosas dejarían de existir (De Aquino, 1951/2001a, I, q. 19, a. 4, sol.).

Una vez explicado qué tipo de relación es la creación de Dios, surge la siguiente pregunta ¿De qué manera Dios creó el mundo? La creación de Dios (ברא/bârâ) es ex nihilo ${ }^{9}$. Es decir, la creación de Dios no tenía ningún referente previo más que sus formas elementales, es decir, sus ideas (De Aquino, 1951/2001a, I, q. 44, a. 3, sol.). Estas formas elementales serán las que informarán a la materia y constituirán al ente en cuanto "aquello cuyo acto es existir"10 (véase def. IV).

El ente es ente en virtud de su tipo de posicionamiento, su valor es tético ${ }^{11}$. En este sentido, 'ex-sistere' indica que el ente existe en virtud de su posicionamiento fuera de algo; esto es, su raíz: Dios (De Saint-Victor, 1958, IV, c. 12/f. 160b9-160c20). Así, la relación de las criaturas con Dios es la de estar por fuera de él - lo cual justifica su grado de imperfección-y predicar existencia de ellas significa que están incompletas, que requieren de su raíz (el Bien) y, por ello, la buscan llamándola "felicidad".

Ahora bien, de esto no se sigue que el ente sea independiente en sentido absoluto de Dios, sino que su condición ontológica es la de estar por fuera de Él. Al estar fuera de Él, el ente adquiere su valor por respectividad (es creado [ex-siste: está por fuera de su raíz] en virtud de un creador). Por el contrario, la conservación existencia del ente se debe, como ya se había mencionado, al acto comunicador de las formas por parte de Dios (De Aquino, 1998, II, cc. 6, 11, 13; 1951/2001a, I, q. 104, a. 1, sol.). Así, la única necesidad aceptada por esta visión judeocristiana es la de la existencia del ente por la voluntad de Dios, pero no viceversa, $y$, mucho menos la autosuficiencia

9 Por otra parte, la teoria creacionista introduce el concepto 'nada' (יאמ/nihil) en II de Macabeos 7:28 para sostener un tipo de acto propio y exclusivo de la comunicación divina (ברא/bârâ) (De Aquino, S. $T .$, I, q. 45, a. 5). Véase def. 2 y su respectiva nota al pie.

10 Este concepto de 'ex-sistente' como "aquello cuyo acto es estar fuera de su raiz" es definido con propiedad por primera vez por Ricardo de San Victor, aunque ya era usado por san Agustín en este sentido creacionista y por los romanos en un sentido de "emanar de" o "salir fuera de" por Cicerón, Lucrecio, entre otros (véase 1.2).

11 Entiéndase 'tético' en el sentido de $\theta \varepsilon \dot{\sigma} \sigma \varsigma$, es decir, "colocación, disposición" (Lydell \& Scott, 1996, voz $\theta \eta \dot{\sigma} \iota)$. 
del ente, como lo muestra la prohibición 6 del anexo 1. Sobre esto Maimónides afirma (2006):

El fundamento básico de la Torá y el principio central de la sabiduría consiste en saber que existe un ser primordial, el cuál creó todo lo que existe, siendo que todo lo existente, en los cielos, en la tierra y entre ambos, no existe sino por la esencia de su existencia. Si se conjeturara que Él no existe, ningún otro podría existir. Si se conjeturara que todo lo existente fuera de él no existiera, Él existiría y no dejaría de existir por la no existencia de los demás seres, ya que todo lo existente lo necesita, y en cambio El Eterno no necesita ni siquiera de uno de ellos. Por lo tanto, su esencia no es como la esencia de ningún ser. (c. 1, \$\$1-3)

\section{La voluntad y la necesidad}

En base a la teoría de la creación los medievales ofrecieron dos vías para el conocimiento de Dios: quia (por los efectos) y propter quid (por las causas/por su esencia). Ante esto, se generaron dos posturas para interpretar la voluntad divina: la voluntarista (sostenida por Agustín [1947a] y franciscanos [Escoto, 1960; 1968]) y la intelectualista (De Aquino, 1951/2001a, I, q. 83).

La primera postura afirma que la voluntad de Dios, dada su infinitud y perfección, opera sobre leyes que exceden a nuestro intelecto. De esta manera, la voluntad divina no puede ser determinada por el intelecto, sino, a lo sumo, por ella misma. “[...] No es determinada naturalmente ni por sí ni por otro, sino que, una vez dada la aprehensión del objeto, tiende deleitosa y electivamente al objeto, incluso cuando no puede no tender" (Escoto, 1968, q. 16, res.). La segunda postura reconoce que en Dios sí hay leyes que puedan ser conocidas y que, además, hay necesidad en algunas cosas que él ha creado. Para esta postura se concibe al entendimiento como "más digno que la voluntad" (De Aquino, 1951/2001a, I, q. 83, a. 3).

Según la exposición anterior, la primera postura sostendría que para Dios sí es posible violar las leyes de la lógica porque su potencia está por encima de cualquier cosa creada o finita (Escoto, 1960); la segunda, por su parte, que no las puede violar (De Aquino, 1998, II, c. 25, $\$ 4$ ). A pesar de esto, ambas posturas aceptan lo siguiente: comprender la esencia y propiedades de Dios de manera absoluta solo es posible si 
la naturaleza divina se le revela al entendimiento humano. Sin mencionar que, "[... a cualquier entendimiento creado le resulta imposible comprehender a Dios" (De Aquino, 1951/2001a, I, q. 12, a. 7, sol) $)^{12}$.

Es posible ver que no hay convergencia en la forma como se entiende la intervención de Dios en la existencia del ente y, con ello, también su individuación; no obstante, dado que la propuesta de Tomás fue adoptada por la Iglesia como la más canónica, se explicará en el apartado siguiente la teoría tomista de la individuación y en el siguiente la visión moderna de las críticas a esta postura.

\section{Avicena y Tomás: la materia como principio de individuación}

Ya en tiempos antiguos tanto Platón (2014) como Aristóteles (2011) habían explicado desde sus respectivas teorías cómo las substancias eran producto de un proceso de información de la materia por un voũc que permite la ordenación de los elementos y, además, la generación del movimiento mismo en el ser.

Según Aristóteles, las causas intrínsecas del movimiento son los contrarios (2011, II, 195a10). Pero, dado que la substancia es un compuesto, es necesario decir que "[...] el substrato es uno en número, pero dos en cuanto a la forma (pues lo numerable es el hombre o el oro o, en general, la materia, ya que es sobre todo la cosa individual, y no es por accidente como generado llega a ser de ello; en cambio, la privación y la contrariedad son solo accidentales)" (2011, I, 190b22-27). Se dice que es "dos en cuanto a la forma" porque la forma contiene tanto al ser como al no ser de esa substancia. La materia, dado que solo puede contener un solo estado (el actual), es unitaria; por eso, "[...] la materia es principio de individuación” (Beuchot, 2009, p. 6). Con esto, la materia es un sustrato o receptáculo de la forma por medio de la cual recibe su condición de "entidad" al ser informada.

Tanto Avicena como santo Tomás comprendieron lo que esto implicaba. Para el primero: "La forma corporeitatis, en tanto que es corporeidad, es una sustancia, una, simple, actual, que no posee diversidad de ninguna clase. [...] Todo cuerpo, sin duda alguna, posee propiamente un lugar, pero no tiene lugar propio en tanto que es un

12 Este tema ya ha sido trabajado en otros espacios (Hernández, 2017); así que no se profundizará con mayor detalle a la teoria de ambas posturas, sino que se recomienda al lector a remitirse a dicha fuente para complementar esta sucinta explicación. 
cuerpo; así que sin duda alguna lo tiene propiamente por medio de una forma que él posee" (Avicena, 1950, c. 13, pp. 111-113). Por esto, llega él a la conclusión de que “[...] el principio de individuación es la materia” (p. 111).

A partir de lo anterior, santo Tomás pretende llegar a la misma conclusión: "La materia es el principio de individuación” (De Aquino, 1963, c. 2, \$5; 1998, I, c. 21, §3; Owens, 1994). Sin embargo, es preciso hacer hincapié en que ambos autores solo se refieren a la materia signata, es decir, aquella que ya ha recibido su acto por la información (o sea, materia actualizada).

Tal como vimos en la definición VII, santo Tomás, afirma que la esencia solo es predicable de los entes particulares (substancias primeras), no de sus géneros (substancias segundas), puesto que los primeros exigen una existencia real, pero los otros no (De Aquino, 1963, c. 2, \$2).

\begin{abstract}
Ahora bien, esta materia no se pone en la definición del hombre en cuanto hombre, pero sí habría que ponerla en la de Sócrates, si Sócrates tuviera una definición. Porque en la definición del hombre no se incluye este hueso y esta carne, sino el hueso y la carne en absoluto, que son la materia no signada del hombre. (De Aquino, 1963, c. 2, \$5)
\end{abstract}

Lo anterior tiene su razón de ser por el tipo de creación que presente en la generación misma de las cosas. Según Tomás, las causas ejemplares proceden de Dios, pues son sus ideas que sirvieron de base para que la creación divina se efectuara (De Aquino, 1951/2001a, I, q. 44, a. 3, sol.). La creación corpórea, continúa diciendo, es producto de Dios porque "[...] todas las cosas, por muy diversas que sean, coinciden en algo común a todas: el ser" (I, q., 65, a. 1, sol.). Grosso modo, el argumento principal que ofrece Tomás es el siguiente:

\footnotetext{
Ahora bien, es característica propia del individuo el no poder estar en varios sujetos. Lo cual sucede por dos razones. Primera, porque su propia naturaleza le impide estar en un sujeto, y este es el caso de las formas inmateriales separadas, que subsisten por sí mismas y se individúan por sí mismas. Segunda, porque tanto las formas sustanciales como las accidentales tienen como exigencia el existir en un sujeto, y no en varios, como es el caso de la blancura, que está en este cuerpo. (De Aquino, 2001b, III, q. 77, a. 2, sol.)
} 
La materia debe ser el elemento individuante de la substancia porque le exige a la forma delimitarse en la existencia concreta, en el ente cuantificado; "[...] puesto que estas formas tienen como exigencia natural el existir en otro como en su propio sujeto, por el que son recibidas en una materia, no estando esta materia sustentada en otro, tampoco esas formas se sustentarán en otro" (De Aquino, 2001b, III, q. 77, a. 2, sol.). Esta es, pues, expuesta de manera breve, la teoría de la individuación de Tomás.

En síntesis, se puede resumir la visión cristiana de la siguiente manera: la voluntad de Dios es absoluta e infinita; así, la existencia de los entes depende únicamente de Él. Su voluntad es incondicionada, pero se le puede conocer por vía de sus efectos (su creación). Además, su relación es virtual y unidireccional; lo cual implica que ningún efecto lo imposibilite de hacer las cosas de otra manera o deshacer alguna acción que haya tomado. Por último, el principio de individuación se sustenta en la información que hace Dios a la materia no signada; lo cual implica que la individuación de los entes depende fundamentalmente de Él.

Ahora bien, una vez explicada la doctrina oficial según la cual creemos que Tamburini y Retz realizaron sus prohibiciones, es preciso continuar este estudio explicando de manera sucinta cómo estos mismos tres temas (la creación y conservación de la existencia, la libertad y la voluntad divina y la individuación) son abordados por los modernos (específicamente, Descartes, Spinoza y Leibniz) para exhibir los contrastes entre estos dos paradigmas y evaluar finalmente si las prohibiciones fueron o no justas (o, si se quiere, justificadas).

\section{La mirada moderna de estos temas}

Teniendo en cuenta los elementos propios de la crítica en las prohibiciones, se procederá, a continuación, a explicar la visión moderna respecto a estos asuntos, basándose en las teorías de Descartes, Spinoza y Leibniz para evaluar si dichas prohibiciones son acertadas $\mathrm{o}$, por otra parte, arbitrarias.

\section{Creación y conservación de los entes}

Tomaremos lo anteriormente expuesto en 1.3 como argumentos generales acerca de cómo una postura determinista conlleva a negar la omnipotencia y, con esto, la existencia de Dios. Teniendo en cuenta esto, salta a la vista que uno de los temas importantes 
resulta ser el de la generación/creación misma del mundo como efecto primario de la labor divina. La posición de Leibniz sobre este aspecto es ya bien conocida. Para Leibniz la explicación sobre el origen del mundo necesita una previa información sobre el origen del mismo. Por ello, trataremos de exponer la posición cartesiana y leibniziana sobre el origen del mundo para resolver la cuestión de por qué se le prohíbe en los claustros universitarios granadinos. Para ello conviene, entonces, observar la posición de Leibniz sobre el tema en cuestión:

\section{[...] Existen en la naturaleza numerosas perfecciones, completamente diversas, que Dios las posee todas a la vez y que cada una le pertenece en su más alto grado. [...] el poder y la ciencia son perfecciones y en tanto pertenecen a Dios no tienen límites. De aquí se sigue que como Dios posee sabiduría suprema e infinita, obra de la manera más perfecta no sólo en sentido metafísico sino además moralmente hablando. En lo que a nosotros respecta, esto se puede expresar del modo siguiente: mientras más nos iluminen e informen las obras de Dios, tanto más dispuestos estaremos a encontrarlas excelentes y absolutamente capaces de satisfacer todo lo que pudiéramos haber deseado. (Leibniz, 1982a, \$1/GP, IV, 427)}

De lo anterior podemos decir varias cosas: 1) al concebir a Dios con una sabiduría infinita Leibniz está convencido de que Dios, al crear el mundo, tuvo en cuenta a todos los otros mundos posibles y eligió crear este porque es el mejor; 2) debemos prestar atención a la aclaración del modo perfecto de la obra moral divina. Esto último se debe a la justificación de Dios y el origen del mal en la Teodicea; pues no es pensable un mundo sin sufrimiento ( $\sin$ mal) porque estas condiciones acompañan al ser finito; 3 ) 'lo mejor' está dentro de las normas a las que el mismo Dios debe ajustarse, y él no elige nada sin una suprema razón (Leibniz, 1877, \$\$8-9). Por consiguiente, Dios está sujeto a las leyes lógicas y al principio de no contradicción $(\$ 3)$; a las leyes morales que obligan a los hombres $(\$ 37)$; y a las formas de las cosas $(\$ 335)$. Dicho esto, es imposible que haya creado algo en contradicción con estas leyes. Por estos límites, que evidentemente están en contraposición con la doctrina escotista (Escoto, 1960, IV, concl. 9; 1968; q. 12), se hace evidente una de las razones por las que se prohíbe a Leibniz en los claustros: ya que supone límites internos a la expresión divina ${ }^{13}$.

13 Curiosamente, santo Tomás también sugiere límites en la omnipotencia divina (De Aquino, 2007, II, c. 25), con ligeros matices, basándose en los dos tipos de necesidad (por sí o por relación), aludiendo a esta segunda. Dado que la necesidad por relación corresponde a los hechos contingentes, su tipo de conocimiento es quia y no propter quid; asi, no se negaria la esencia de Dios, sino tan solo se 
Ahora bien, evaluemos brevemente la posición de Leibniz respecto a la armonía preestablecida. Para Leibniz el mundo sensible (los cuerpos) son expresiones de una realidad fundamental (monádica) para la que no hay interacción, sino más bien representación mutua según la armonía preestablecida, limitándose a reflejar el orden universal fundado en la mónada divina (Leibniz, 1982c, $\$ 56 ; 1877$, $\$ 130$ y 360). Esta resulta ser otra prueba de la existencia de Dios; ya que de sus efectos (de la contingencia del mundo) podemos remontarnos a la sustancia originaria y necesaria ${ }^{14}$ : "Y, así la razón última de las cosas debe estar en una substancia necesaria, en la cual el detalle de los cambios no esté sino eminentemente, como en su origen; y esto es lo que llamamos Dios” (\$38).

Así pues, no hay posibilidad de que Dios sea incapaz de hacer algo - como, por ejemplo, regresar alguna sustancia a la nada (Tamburini, 2004, an. 1, \$8) -, pues la omnipotencia es una de sus cualidades, según la tradición (De Aquino, 1951/2001a, I, q. 25; Escoto, 1968, q. 7).

La prueba de Descartes también es hecha quia, es decir, por sus efectos. Recordemos que, para la tercera meditación, el filósofo francés ya había admitido que, desde su consideración formal, todas las ideas eran imágenes o representaciones de su entendimiento (Descartes, 2014, AT, VII, 34-35). No obstante, consideraba que existe una jerarquía ontológica de sustancias: infinitas (como Dios), finitas (como el 'yo') y accidentales (ideas generadas o propias) (AT, VII, 37; 53). La realidad objetiva se entiende como el grado de realidad formal de lo que representan; es decir, qué tan claro y distinto - en términos de "lo que es cognoscible" - es para el entendimiento (AT, VII, 40-41). Por ello, las ideas de accidentes son inferiores a las ideas de sustancias en cuanto poseen más realidad objetiva. En este modelo, el efecto debe provenir de una causa que tenga, al menos, el mismo grado de realidad objetiva que el efecto. Ahora bien, ¿puede ser el 'yo' el origen de Dios (en tanto que sustancia infinita) siendo el 'yo' sustancia finita? La respuesta de Descartes es la siguiente:

determinarian los tipos de efectos que se generarian. Parece ser que la tradición optó por conservar la visión escotista por encima de la tomista a este respecto; afirmando que Dios podría hacer cosas que parecerian incluso ilógicas a nuestro intelecto (Escoto, 1960, IV, concl. 9).

14 Es decir, sería un conocimiento quia. Téngase en cuenta que Tomás también cree que pueden darse argumentos a favor de la existencia de Dios partiendo de sus efectos (que serían las cinco vías [De Aquino, 1951/2001, I, q. 3, sol.]). Parece ser que, de nuevo, la objeción iria más orientada al voluntarismo escotista que al racionalismo tomista. 
Con el nombre de Dios entiendo cierta sustancia infinita, independiente, supremamente inteligente, supremamente poderosa, por quien, tanto yo mismo, como todo lo demás que existe, si algo más existe, hemos sido creados. Todo lo cual es en verdad de tal naturaleza, que entre más cuidadosamente lo considero, menos me parece que haya podido proceder sólo de mí. Por lo tanto, de lo dicho anteriormente hay que concluir que Dios existe necesariamente. (Descartes, 2014, AT, VII, 45)

Para Descartes lo infinito no se manifiesta por su negación, sino que más bien se manifiesta porque hay más realidad en la sustancia infinita que en lo finito. Además, dice poseer en él más “[...] la percepción de lo infinito que de lo finito, esto es, de Dios antes que de mí mismo" (AT, VII, 45). Sin embargo, la posición de Descartes acerca del universo es mecanicista; en otras palabras: después de que Dios creó al mundo no volvió a intervenir (Pascal, 1948, fr. 77). Por ello, indica que "No deben examinarse las causas finales de las cosas creadas, sino sus causas eficientes" (Descartes, 1989, AT, VII, $\$ 28)^{15}$. En este caso no pueden detectarse o interpretarse rastros de armonía preestablecida ni la idea de un plan divino.

De lo anterior radicaría una de las diferencias con Leibniz, puesto que este último afirma: "Y en general siempre que vemos que algo ofrece notables utilidades, podemos declarar con seguridad que el propósito de Dios fue producir ese fin, entre otros, esto es, proporcionar aquellas ventajas, puesto que no sólo conoció sino procuró esa utilidad" (Leibniz, 1982d, art. 28/GP, IV, 360-361). Así las cosas, ambos poseerían problemas importantes para la doctrina de la Colonia.

Por un lado, Leibniz, al concebir una armonía preestablecida, limita a Dios a operar bajo las leyes que Él mismo ha creado. Por otra parte, Descartes deja de lado el plan divino por considerar que es imposible saber si Dios nos hace partícipes de sus planes;

15 Este giro en el que se privilegia el énfasis a la causa eficiente por encima de la causa final proviene del renacimiento, donde en el hilemorfismo tradicional la forma (que era central en los debates escolásticos) es reemplazado por Bernardino Telesio (2009) por el concepto 'fuerza' cuyos opuestos son el calor y el frío (I, c. 19), que no es ya algo cognoscible de manera abstracta, sino a partir de la experimentación a partir de una "disección", pues dicho agente del movimiento es intrínseco y no extrínseco -como sí pasa con el paradigma escolástico, para quienes las formas advienen por la conservación que hace Dios de los entes-. Esta idea es apropiada por Bacon (1985) (y con él, toda la Modernidad [Arana, 2012, p. 259]) al utilizar el término "extracción" de la verdad/los axiomas $(N O, \mathrm{I}, 11)$ para anticiparse a la naturaleza por medio de un enfrentamiento con ella (I, 26, 28, etc.). Asi, los principios de la naturaleza se deben estudiar dentro de la naturaleza misma y las causas eficientes que tienen unas substancias sobre otras. 
en principio porque, usando la luz natural que ha puesto en nosotros (Descartes, 2011), solo podemos conocerle mediante sus efectos - mejor dicho; a partir de sus atributos, o sus efectos en nosotros-. En otras palabras, la comprensión de las causas primeras está fuera de nuestro alcance y comprensión (Descartes, 2014, AT, IX, 184-187), y por esta razón solo podemos intuir sus efectos.

\section{Libertad y determinismo}

Durante la Edad Media se discutió con renovado vigor la cuestión de la compatibilidad o incompatibilidad entre la libertad humana y la presciencia divina (De Aquino, 1951/2001a, I, q. 82; Escoto, 1968, q. XVI). El problema que enlazó en la Edad Moderna las cuestiones sobre voluntad y determinismo fue el siguiente: ¿puede decirse que el hombre es libre cuando hay determinismo en la naturaleza? Según las prohibiciones reconstruidas en el punto segundo de 1.3, trataremos de dar respuesta brevemente desde las posiciones de Leibniz, Descartes y Spinoza. La pregunta que conecta a los tres autores es: ¿cómo se sostiene la omnipotencia de Dios sin renunciar a la libertad del hombre?

En primer lugar, Descartes afirma que es imposible conciliar ambas posturas. Descartes de entrada asume - como habíamos visto- la omnipotencia de Dios y su infinitud como principios. Además, postula la inmutabilidad de Dios en el sentido de "causa que produce siempre el mismo efecto", puesto que solo la regularidad inalterable de la relación causal puede darle sustento al conocimiento de la naturaleza como universal y necesario (Descartes, 2014, AT, IX, 439). Para Descartes el motivo de nuestros errores no se funda en la determinación divina, sino en nuestra condición finita; erramos por defecto de nuestra acción y no de nuestra naturaleza (Descartes, 1989, AT, VII, \$38). Así las cosas, no somos libres en el sentido de no estar predeterminados, sino más bien que dada nuestra condición nos es imposible saberlo. Por ello, quedamos subsumidos en el reino de la necesidad de nuestra condición finita. Como vemos, Descartes reduce a un rígido mecanicismo - a un orden necesario - todo el mundo de la naturaleza, pero excluye de este determinismo al hombre en cuanto sustancia pensante.

Por otra parte, para Spinoza la libertad se define como:

Aquella cosa que existe por la sola necesidad de su naturaleza, y se determina por sí sola a obrar. Necesaria, en cambio, o más bien coaccionada, aquella que 
es determinada por otra a existir y obrar según una razón cierta y determinada. (Spinoza, 2000, I, def. 7/OP, 2)

Según esta definición de 'libertad', no hay contradicción entre libertad y actuar "por la sola necesidad de la propia naturaleza". Al contrario, en eso mismo consiste la libertad. No obstante, es posible distinguir que la libertad humana es muy distinta de la libertad de Dios, puesto que la esencia humana es un producto o efecto de Dios, mientras que la esencia de Dios no tiene una causa exterior, porque Dios es causa sui (I, prop. 1/ $\mathrm{OP}, 1)$. Por esto, la libertad divina es absoluta, mientras que la humana es relativa a la esencia que Dios ha producido en lo humano.

Spinoza es muy consecuente con esta definición de libertad al afirmar que Dios no puede producir las cosas de un modo distinto a como han sido producidas (I, prop. $33 / O P, 72$ ), puesto que su naturaleza es una sola. Dios mismo no puede cambiar arbitrariamente las leyes que rigen la realidad, las cuales son expresión de su naturaleza. Esto no denota ninguna imperfección en Dios, salvo para quienes conciben a Dios imaginativamente, como un príncipe que decreta cosas según el mero capricho. Finalmente, libertad no es sinónimo de arbitrariedad, sino de actuar en concordancia con nuestra esencia necesaria (III, props. 6-7/OP, 102). No hay, en términos de Spinoza, una contradicción real entre determinismo y libertad, como pudiera creerse, esta sólo existe entre determinismo y arbitrariedad.

Leibniz, por otra parte, suscribe una definición distinta de la libertad en el hombre. Según él, "todas las acciones están determinadas y nunca son indiferentes" (Leibniz, 2011, p. 177). Esto último en virtud de la razón suficiente y la armonía prestablecida. En ella existe una razón inclinante, que determina, pero no constriñe; es decir, no es la causa de actuación en contra de la voluntad (p. 177). Esta inclinación sería un reflejo de la protomónada. En otras palabras, Leibniz logra conciliar el determinismo con la voluntad indicando que:

[...] En tanto que poseemos luces y obramos según la razón, nos vemos determinados por las perfecciones de nuestra propia naturaleza y, por consiguiente, seremos más libres y estaremos menos embarazados por la elección. Es cierto, que todas nuestras perfecciones, así como las de la naturaleza, provienen de Dios, pero, lejos de que esto sea contrario a la libertad, es justo por ello que 
somos libres, ya que Dios nos ha comunicado un grado de perfección y de libertad. (Leibniz, 2011, p. 178)

En otras palabras, participamos en la libertad de Dios a través de la inclinación intrínseca para obrar bien que existe en nosotros. Esta libertad es la más deseable, no solo por ser la más razonable, sino porque es la más próxima a Dios (la cual nos predispone a obrar y elegir bien). "Por lo tanto el que ama a Dios considera al pasado como un bien y se esfuerza por mejorar el mundo” (Leibniz, 1982b, S 110).

Como conclusión podemos señalar lo siguiente: Descartes postula un mecanicismo que, si bien regula la naturaleza, deja lado la voluntad divina como legisladora de las acciones humanas y, con ello, exime de responsabilidad moral a Dios. Spinoza, por otra parte, salva, parcialmente, la libertad del hombre, indicando que Dios es el único ser plenamente libre. En cambio, los seres humanos, así como todas las cosas singulares o finitas, poseemos una libertad relativa a nuestra esencia. Finalmente, Leibniz resuelve el problema, acudiendo a la armonía prestablecida y la razón suficiente para afirmar que lo predeterminado de nuestras acciones es un impulso para permitirnos que nuestras inclinaciones operen hacia el Bien. La primera postura estaría contrariando tanto a la visión intelectualista como a la voluntarista (siendo la más problemática); la segunda, iría a favor de la voluntarista (Escoto, 1968, q. 16); la tercera, con la intelectualista (De Aquino, 1951/2001a, I, q. 82, a. 1).

\section{Individuación en Leibniz}

Resta un último aspecto a considerar dentro de las prohibiciones: la individuación. Esta última puede verse censurada mediante las dos tesis del anexo 3 por el padre Retz. Para esto se explicará la teoría de la individuación de Leibniz y se mostrará qué tanta diferencia hay entre esta postura con la de Tomás.

Antes de explicar la postura de Leibniz es preciso mostrar que la propuesta de la teoría de la individuación de Avicena y Tomás ya habían sido criticadas por Averroes (1919) y Escoto (1960, II, concl. 8), quienes apelan a la Física, donde Aristóteles llega a afirmar que “[...] la forma es una, como el orden o la música o cualquier otra determinación similar" (190b29). En este sentido, la forma misma es aquello que hace a esta cosa ( $\tau$ ò $\delta \varepsilon$

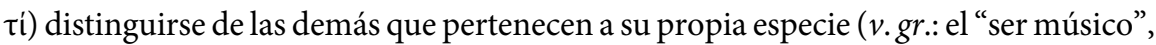
"ser genio", “ser austriaco” y muchísimas más, de Mozart respecto a los demás 
hombres $)^{16}$. La diferencia entre la postura de Averroes y la de Escoto en este asunto consiste en que el primero afirma que dichas formas serían de carácter universal como se muestra en el ejemplo (Averroes, 1919, I, \$35), mientras que el segundo afirmaría que son "[...] determinaciones formales o específicas" (Beuchot, 2009, p. 21), es decir, la haecceitas, cambiando los predicados anteriores, por ejemplo, de "ser músico" a "ser músico asî" o "ser este tipo de músico".

Ante esta postura, igualmente Guillermo de Ockham (1994) y Francisco Suárez (1960) optarán por una perspectiva distinta: el principio de individuación debe abarcar al ente en tanto substancia individual y no según sus partes. Para ello se basaron en el mismo libro y capítulo de la Física, el cual reza así:

Por eso, en un sentido hay que decir que los principios son dos, y en otro que son tres. En un sentido son los contrarios, como en el caso del músico y el a-músico, o del calor y el frío, o de lo armónico y lo inarmónico; pero en otro sentido no lo son, ya que es imposible que los contrarios se afecten entre sí. Pero esta dificultad puede resolverse también porque hay otro término, el substrato, que no es un contrario. Por consiguiente, en cierto sentido los principios no son más numerosos que los opuestos, sino que, por así decirlo, son dos en número; pero, en otro sentido, como en cada uno de ellos hay un ser distinto, no son ya dos, sino tres. (Aristóteles, 2011, I, 7, 190b29-191a1)

Así, tanto para Ockham como para Suárez el principio de individuación estribaría en el compuesto mismo del ente. La materia tiene en sí misma su actualidad, pues su esencia no se puede distinguir de su existencia (es decir, es lo que es apelando, no a principios sobrenaturales, sino que dichos principios se pueden encontrar en la existencia misma del ente). La única diferencia entre ambos autores es que Ockham asume que dicha materia es la privación de las formas, sustentando así su nominalismo, según el cual no existen entes universales, sino que los términos "'hombre' y 'hombres' significan lo mismo” (De Ockham, 1994, I, c. 44/OPh, 139) ${ }^{17}$. Francisco Suárez, por otra parte,

16 Nótese la similitud de esta postura con la muy tardia teoria de las descripciones y los nombres propios asumida por autores como John Searle (2012), quien afirma que el significado de un nombre está en el cúmulo de descripciones definidas que se le puedan predicar a este.

17 Esta postura será favorecida posteriormente por autores como Kripke (2017) porque, además de solucionar el problema de la individuación a entes reales, también permitiría solucionar cuál es el principio de individuación para entes abstractos (como Pegaso) al tomar al nombre como un designador rígido de la identidad (pp. 10-11). 
a pesar de reconocerle entidad propia a la materia (como también lo hace Ockham), no ve a esta como algo perfecto, sino al contrario (como algo inacabado), dada su condición de potencialidad (Beuchot, 2009, p. 13). De esta manera, para Suárez tanto la materia como la forma esencial son igualmente individuantes en la existencia del ente y cumplen un rol igual de importante (Suárez, 1960, disp. 13, sect. 4, n. 9).

De otra parte, la postura que tomará Leibniz frente a este asunto será más cercana a Suárez, solo que será más radical: el principio de individuación radica en la totalidad de las propiedades del ente - incluyendo las accidentales - bajo un mismo espacio y tiempo.

Pero ¿qué queremos cuando numeramos, o sea cuando decimos esto (pues numerar es repetir esto), ¿qué es esto o bien la determinación? ¿Qué es sino la percepción del tiempo y del lugar o sea del movimiento de una cosa dada con respecto a nosotros, o con respecto a una cosa ya determinada o bien nuestro propio movimiento (por ejemplo, el movimiento de la mano o el dedo con que señalamos) o el movimiento de una cosa ya determinada, como el de un bastón apuntando a la cosa que hay que mostrar? Estos son por lo tanto los principios de individuación que te asombraban fuera de la cosa misma: pues (a partir de la hipótesis de la máxima semejanza) ningún ángel o, para decirlo con audacia, ni siquiera $\operatorname{Dios}^{18}$, puede asignar otra distinción entre aquellos huevos que ésta: ahora éste se halla en el lugar A, aquel en el lugar B. (Leibniz, 1982b, S 125-126)

Según lo anterior, parecería que efectivamente el espacio y el tiempo son los principios de individuación y no las propiedades del ente en cuanto tal, pero no es eso lo que el filósofo alemán nos quiere indicar. Aunque espacio y tiempo son las condiciones de discernimiento e individuación de un ente, es el reconocimiento de dichas propiedades bajo las mencionadas condiciones lo que garantiza, de hecho, un adecuado reconocimiento de su individuación. Según lo anterior, podría distinguirse, por ejemplo, dos huevos que sean prácticamente idénticos por no tener uno una propiedad respecto del otro bajo el mismo espacio y tiempo: el lugar. Así, pues, siendo espacio y tiempo condiciones extrínsecas y las propiedades condiciones intrínsecas, el principio de individuación de Leibniz parece ser la teoría más abarcativa (y, en cierta medida, ecléctica) de todas las anteriores posturas.

18 Subrayado fuera del texto. Nótese cómo esta parte podria ser una objeción según la cual Leibniz podría estar negando la omnipotencia de Dios al indicar que ni él puede violar el principio de individuación 
Lo anteriormente mencionado parece resolver el problema. No obstante, surge la siguiente pregunta: ¿cómo son posibles las condiciones accidentales? Esto solo puede resolverse en lo ya explicado arriba sobre la armonía preestablecida (Leibniz, 1877, $₫$ 105), porque tanto las relaciones como las esencias de los entes ya están predefinidos por la mente de Dios. Esto le permite concluir a Leibniz lo siguiente: "Yo soy un individuo; [Él] me crea y conserva como tal; siendo todo lo que yo soy en este instante con todas mis dependencias" (Leibniz, 1877, \$336). Leibniz afirma, efectivamente, que tanto la esencia como las operaciones entre los entes (lo que generaría a los accidentes) son condiciones necesarias para la individuación, sin embargo, sí reconoce una prioridad en la esencia sobre las operaciones:

Cuando Dios produce la cosa, la produce como un individuo y no como un universal de lógica, lo reconozco; pero produce su esencia antes que sus accidentes, produce su naturaleza antes de sus operaciones, según la prioridad de su naturaleza, e in signo anteriore rationis. (Leibniz, 1877, § 390)

Con lo anterior Leibniz resuelve el asunto de la siguiente manera: efectivamente la esencia es primera en las substancias. Pero, las operaciones son también condiciones necesarias para reconocer la individuación, porque dichas operaciones están impresas en la creación de la esencia. Con esto, la importancia de la esencia se conserva, pero también es tenida en cuenta la totalidad absoluta de las propiedades del ente, aplicándose, ahora sí, una identidad genuina entre esencia y existencia (como Ockham y Suárez pretendían afirmar).

Dado que la anterior postura explica de mejor manera el principio de individuación, debemos preguntarnos por qué esta teoría fue censurada en dicha época por Retz. Tres posibles razones surgen al respecto: la primera (y más evidente), porque derrumba la posición tomista; la cual era ya tomada como canónica y preferible (puesto que esta daba un sustento a la transubstanciación [De Aquino, 2001b, III, q. 77]). La segunda, porque exigía un cambio de paradigma similar al que exigía la visión cartesiana: el principio de individuación exigía un análisis del ente mismo y no de Dios en tanto que principio informante, ya que, si bien es cierto que Dios es la causa primera de todos los entes, una vez han sido creados ya basta con analizar a este en su condición actual para comprender su esencia (Leibniz, 1877, \$241). Y el tercero y último aspecto es que Leibniz, como ya hemos mencionado, termina sosteniendo una visión determinista de los hechos; 
Como Dios no puede hacer nada sin razón, ni siquiera cuando obra milagrosamente, se sigue de ahí que no tiene sobre los sucesos individuales ninguna voluntad que no sea una consecuencia de una verdad o de una voluntad general. (Leibinz, 1877, §206).

\section{Conclusiones}

Para concluir este análisis es preciso evaluar las siguientes cuestiones: ¿son justas las prohibiciones? ¿Qué impacto surge del choque entre las correspondientes respuestas de cada paradigma? ¿Es o no visible el cambio o transposición entre paradigmas?

Ante la primera y segunda preguntas es posible ver que las censuras a Descartes y Spinoza sí parecen ser atinadas, pues sí ponían en riesgo los fundamentos de la religión cristiana: la omnipotencia y la comunicación del bien de Dios (es decir, su independencia respecto a su criatura). La omnipotencia y necesidad de Dios, por una parte, serían negadas si se apoya una visión mecanicista del mundo, esto último implica que el conocimiento y búsqueda de Dios es innecesaria, pues es incognoscible. La independencia de Dios respecto a las criaturas también sería problemática en la postura de Spinoza, pues en su visión nosotros (las criaturas) no seríamos más que ciertos modos de esa unitaria e infinita substancia: Dios. La tercera postura (de Leibniz), dada la cercanía que tiene con Tomás y la escolástica (Beuchot, 2009, pp. 13-14), no pareciera ser digna de ser censurada respecto al determinismo - pues esto no niega la libertad del hombre ni de Dios - ni respecto a la creación y conservación de las substancias, pues también asume que el mundo y su orden se deben a Dios en tanto creador y ordenador de todas las cosas, en sus palabras como Unidad Dominante (Leibniz, 982f, GP, VII, 302 y ss.).

No obstante, la individuación leibniziana sí parece tener problemas con la teoría cristiana tomista. En primer lugar, porque afirma que “[...] ni siquiera Dios, puede asignar otra distinción entre aquellos huevos que ésta: ahora éste se halla en el lugar A, aquel en el lugar B” (Leibniz, 1982b, S, 126), lo cual resta a Dios omnipotencia. En segundo lugar, porque las consecuencias que son obtenidas de dicha armonía preestablecida sí podrían poner en riesgo un aspecto importante del cristianismo: la transubstanciación. No es posible que Cristo esté y sea cuerpo en más de un lugar y al mismo tiempo (como pasa con el pan o las hostias), pues ni Él puede violar el 
principio de individuación. Con todo esto, parece que dichas prohibiciones sí son justificadas ${ }^{19}$.

Respecto a la tercera pregunta, efectivamente es posible ver un cambio de paradigma al cambiar el enfoque teocéntrico a uno centrado en el ente real mismo; mientras autores como Aquino consideran crucial el papel de Dios para comprender al ente, autores como Descartes, Spinoza y Leibniz consideran al ente como punto de partida y llegada (claro está, sin negar la existencia o bondad de Dios). En este sentido, es posible ver en dichos autores un esfuerzo incesante por trasladar las investigaciones de la metafísica de una teología con fundamento trascendente a una ontología con principios evidentes en lo inmanente (tarea ya adelantada por Ockham y Suárez). Por último, podríamos indicar que la comprensión del paso de un paradigma a otro permite comprender de mejor manera cuál fue la recepción de dichos autores por parte de las autoridades eclesiásticas - y educativas - de la Colonia y, con ello, adelantar una explicación acerca de la tardanza de algunas teorías filosóficas modernas a Latinoamérica.

\section{Referencias}

Anónimo. (1975). Biblia de Jerusalén. Trad. José Ángel Ubieta (dir.). Bilbao: Descleé de Brower.

Aquinatis, S. T. (1951). Summa theologiae. Pars I. Madrid: Biblioteca de Autores Cristianos.

Arana, J. (2012). Bernardino Telesio, "La naturaleza según sus propios principios". Naturaleza y Libertad: revista de estudios interdisciplinares, 4. 259-264. Recuperado de: https://dialnet.unirioja.es/servlet/articulo?codigo $=4978885$

Aristotelis. (1974). KАТНГОРІАI. En: Categoriae et Liber de interpretatione. L. ManlioPaluello (ed.). Oxford: Oxonii e Typographeo Claredoniano.

19 Se dice que son justificadas desde un contexto cristiano; es decir, tienen una razón de ser. No obstante, no se trata de un carácter moral de la prohibición sino el cambio y los conflictos que surgen dentro de los fundamentos cristianos. Tan solo se quiere decir con esto que, efectivamente, dichas tesis prohibidas si ponian en peligro fundamentos esenciales de la religión cristiana, y no que sencillamente las prohibiciones obedecian a una lectura sesgada y arbitraria por parte de los censores. 
Aristóteles. (2011). Física. En: Candel, M. (Ed.). Obra completa I: Protréptico. Metafísica. Física. Acerca del alma. Trad. Guillermo R. de Echandía. Madrid, España: Editorial Gredos.

Aristóteles. (2012). Categorías. De interpretatione. Porfirio. Isagoge. Trad. Luis Valdés Villanueva. Madrid: Tecnos.

Aristóteles. (2014). T $\Omega$ N META TA $\Phi \Upsilon \Sigma I K A$. En: Metafísica. Trad. Valentín García Yebra. Edición trilingüe. Madrid, España: Gredos.

Averroes. (1919). Compendio de metafísica. Trad. Carlos Quirós Rodríguez. Madrid, España: Edición bilingüe. Imprenta de Estanislao Maestre.

Avicena. (1950). Sobre metafísica. Trad. M. Cruz Hernández. Madrid: Revista de Occidente.

Bacon, F. (1985). La gran restauración. Trad. Miguel A. Granada. Madrid: Alianza.

Beuchot, M. (1981). El problema de los universales. México, D. F.: Instituto de Investigaciones Filosóficas, UNAM.

Beuchot, M. (2009). Introducción. En: Leibniz, G. W. (2009). Discusión metafísica sobre el principio de individuación. México, D. F.: Instituto de Investigaciones Filosóficas, UNAM.

De Aquino, T. (1963). El ente y la esencia. Trad. M. Fuentes Benot. Buenos Aires: Aguilar.

De Aquino, s. T. (1975). De veritate/Cuestiones disputadas sobre la verdad. Ed. bilingüe. Estudios de filosofía, 1(1). 107-130. Recuperado de: http://revistas.pucp.edu. pe/index.php/estudiosdefilosofia/article/view/538/528.

De Aquino, T. (1998). Suma contra los gentiles. Trad. C. Ignacio González. México, D. F.: Porrúa.

De Aquino, s. T. (2001a). Suma de teología. VV. TT. Cuarta edición. Tomo 1 (parte I). Madrid: Biblioteca de Autores Cristianos.

De Aquino, s. T. (2001b). Suma de teología. VV. TT. Cuarta edición. Tomo 5 (parte III). Madrid: Biblioteca de Autores Cristianos. 
De Ockham, G. (1994). Suma de lógica. Trad. Alfonso Flórez Flórez. Bogotá, Colombia: Norma.

De Saint-Victor, R. (1958). De trinitate. J. Rebaillier (ed). Paris: Librairie Philosophique J . Vrin.

Descartes, R. (1989). Los principios de la filosofía. En: Descartes y Leibniz. Sobre los principios de la filosofía. Trad. M. López y M. Graña. Madrid, España: Gredos.

Descartes, R. (2011). Investigación de la verdad por la luz natural. En: Flórez Miguel, C. (Ed.). Obra completa. Biblioteca de Grandes Pensadores. Madrid, España: Editorial Gredos.

Descartes, R. (2014). Meditaciones acerca de la Filosofía Primera. Trad. $1^{\text {a }}$ ed. (del latín) Jorge Aurelio Díaz. Edición trilingüe. Bogotá, Colombia: Universidad Nacional de Colombia.

Escoto, J. D. (1960). Tratado del primer principio. En: Dios uno y trino. Trad. Félix Alluntis, O. F. M. Ed. bilingüe. Madrid: Biblioteca de Autores Cristianos.

Escoto, J. D. (1968). Cuestiones cuodlibetales. Trad. Félix Alluntis, O. F. M. Madrid, España: Biblioteca de Autores Cristianos.

Fuentes Morán, M. T. (2002). “Teil Deutsch-Spanisch”. In: Langenscheidt Diccionario Universal Alemán. Berlín: Langenscheidt KG.

Hospers, J. (1990). An Introduction to Philosophical Analysis. 3rd Edition: London: Routledge.

Hegel, G. W. F. (2011). Ciencia de la lógica. Tomo 1. Trad. Félix Duque. Madrid: Abada. Hernández Rodríguez, J. C. (4 de octubre de 2017). Respuestas a las paradojas sobre la omnipotencia de $\operatorname{Dios}^{20}$. V Congreso de estudiantes de filosofía. Universidad del Quindío, Armenia. Recuperado de: https://www.youtube.com/watch?v=L6Zi-jA_ePs\&t=192s Kripke, S. (2017). El nombrar y la necesidad. Trad. Margarita M. Valdés. México, D. F., México: Instituto de Investigaciones Filosóficas, UNAM.

20 De esta ponencia hay un texto inédito en proceso de publicación en la revista Pensamiento. 
Leibniz, G. W. (1877). Teodicea. Trad. Patricio de Azcárate. En: Obras de Leibnitz. Tomo 5. Madrid: Casa editorial de Medina.

Leibniz, G. W. (1982a). Discurso de metafísica. En: Escritos filosóficos. Trad. T. E. Zwanck. Buenos Aires: Charcas.

Leibniz, G. W. (1982b). Profesión de fe del filósofo. En: Escritos filosóficos. Trad. E. de Olaso. Buenos Aires: Charcas.

Leibniz, G. W. (1982c). Monadología. En: Escritos filosóficos. Trad. E. De Olaso. Buenos Aires: Charcas.

Leibniz, G. W. (1982d). Advertencias a la parte general de los Principios de Descartes. En: Escritos filosóficos. Trad. T. E. Zwanck. Buenos Aires: Charcas.

Leibniz, G. W. (1982e). Principios de la naturaleza y de la gracia fundados en la razón. En: Escritos filosóficos. Trad. E. de Olaso. Buenos Aires: Charcas.

Leibniz, G. W. (1982f). Sobre la originación radical de las cosas. En: Escritos filosóficos. Trad. T. E. Zwanck. Buenos Aires: Charcas.

Leibniz, G. W. (2011). En torno a la libertad y necesidad (pp. 101-106). En: Echeverría, J. (Ed.). Escritos escogidos: Escritos filosóficos. Madrid: Gredos.

Lewis C. T., Short, C. y Freund, W. (1956). Latin Dictionary by Lewis \& Short, Founded on Andrew's Edition of Freund's Latin Dictionary. Oxford: Oxford University Press. Recuperado de: http://www.perseus.tufts.edu/hopper/text?doc=Perseus\%3Atext \%3A1999.04.0059\%3Aentry\%3Drevisio.

Lydell, H. G. y Scott, R. (1996). Greek-English Lexicon. Clarendon: Oxford University Press. Recuperado de: http://www.perseus.tufts.edu/hopper/resolveform? redirect $=$ true

Maimónides. (2006). Sobre los principios del judaísmo. En: Obras filosóficas y morales. Trad. Rabino Aryeh Nathan. Barcelona, España: Ediciones Obelisco.

Owens, J. (1994). “Thomas Aquinas (b. ca. 1225; d. 1274)” (pp. 173-194). In: Gracia, J. E. (Ed.). Individuation and scholasticism: The later middle ages and the counterreformation. New York: State University of New York Press. 
Pascal, B. (1948). Pensamientos sobre la religión y otros asuntos. Trad. Luis R. Contreras. Buenos Aires: El Ateneo.

Platón. (2013). Sofista. Trad. Ant. Trovar. En: Diálogos: Critón. Gorgias. Menón. Fedro. Sofista. Político. Cartas. Ed. bilingüe. Madrid: Centro de Estudios Políticos y Constitucionales.

Platón. (2014). Timeo. Trad. Francisco Lisi. En: Alegre Corrido, E. (Ed.) Obra completa. Tomo 3. Biblioteca de Grandes Pensadores. Madrid, España: Editorial Gredos, S. A.

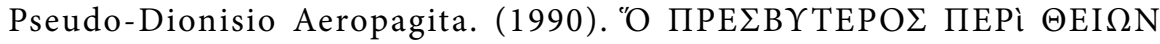

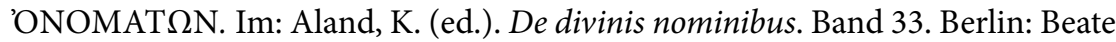
Regina Suchla.

Retz, F. (2004). Prohibición de algunas tesis filosóficas (anexo 3). En: En: Del Rey F., J., y Marquínez Argote, G. (Eds.). Breve tratado del cielo y los astros. Bogotá: Pontificia Universidad Javeriana.

San Agustín. (1947a). Del libre albedrío. En: Obras filosóficas. Trad. Evaristo Seijas. Madrid: Biblioteca de Autores Cristianos.

San Agustín. (1947b). De la naturaleza del bien: contra los maniqueos. En: Obras filosóficas. Trad. Mateo Lanseros. Madrid: Biblioteca de Autores Cristianos.

San Agustín. (1958). De Civitate Dei. En: La Ciudad de Dios. Tomo 2. Edición bilingüe. Trad. José Morán. Madrid: Biblioteca de Autores Cristianos.

Salazar Bondy, A. (1968). ¿Existe una filosofía de Nuestra América? México, D. F.: Siglo XXI.

Searle, J. (2012). Nombres propios y descripciones. Trad. J. Fillol y E. Ujaldón. En: Valdés Villanueva, L. (2012). La búsqueda del significado. Madrid, España: Tecnos.

Spinoza, B. (2000). Ética demostrada según el orden geométrico. Trad. Atilano Domínguez. Madrid: Trotta.

Suárez, F. (1960). Disputaciones metafísicas. 7 vols. Edición bilingüe. Madrid: Gredos. Tamburini, M. (2004). "Prohibiciones de algunas tesis cartesianas y leibnicianas" y "Prohibición de ciertas proposiciones teológicas” (anexos 1 y 2). En: Del Rey F., 
J., y Marquínez, G. (Eds.). Breve tratado del cielo y los astros. Bogotá: Pontificia Universidad Javeriana.

Telesio, B. (2009). De rerum natura iuxta propia principia. En: La natura secondo i suoi principi. Testo latino a fronte. Milano: Bompiani. 